\title{
Techniques of Domestication and Carbon Sequestration of Jatropha curcas Associated with Vigna unguiculata in Marginal Soil of Garoua Region, Cameroon
}

\author{
Tchobsala $^{1}$, Megueni Clautilde ${ }^{1}$, Souare Konsala ${ }^{2}$, Njintang Yanou Nicolas ${ }^{1}$, Sadou Ismael ${ }^{3}$, Patrick Prudent ${ }^{4}$ and \\ Palou Oumarou ${ }^{3}$ \\ 1. Faculty of Science, University of Ngaoundéré, P.O. Box 454, Cameroon \\ 2. Faculty of Science, University of Maroua, P.O. Box 814, Cameroon \\ 3. Institute of Agricultural Research and Development, Maroua, P.O. Box 33, Cameroon \\ 4. Institute of Agricultural Research and Development, Garoua, P.O. Box 415, Cameroon
}

\begin{abstract}
In order to reduce the increase of fuel prices, and improve the living conditions of the population, a study was carried out by Convention No. 1/IRAD/PCS ESA2-SDCC in the region of Garoua in Cameroon. The study aimed to characterize the behaviour of $J$. curcas associated with $V$. unguiculata in marginal soils in the Sahel region in order to improve the livelihoods of the farmers and promote its domestication in rural areas. It also aimed at pointing out the influence of two implantation techniques of $J$. curcas on the germination, the different quantities of NPK and cow dung, planting techniques and association with $V$. unguiculata var. lori on growth parameters of development and yield of $J$. curcas on the degraded marginal soils in the region. The experimental design was a completely randomized block with five levels of fertilization (F0: control; F1: $50 \mathrm{~g}$; F2: $100 \mathrm{~g}$ of NPK 15-20-15; F3: $1 \mathrm{~kg}$ and $2 \mathrm{~kg}$ of cow dung) per plant. Two types of establishment propagator (Ge) and direct seedling (Se) with three replications were used. Data were analysed by Stratigraphic + and XLSTAT. Results showed that the propagator germination was higher than the direct seeding, 95\% and 40\% respectively. The Principal Component Analysis (PCA) of the parameters of growths and yield of J. curcas showed high correlation between the production of the leaves and the length of the leaves $(\mathrm{R}=0.861 ; P \leq 0.001)$. These parameters were correlated with the Biplot (F1 and F2) to 53.24\%. It was opposed to the positives and imperfect correlation between the height and the recover parameters $(\mathrm{R}=0.486 ; P \leq 0.05)$. The treatments $100 \mathrm{~g}$ of NPK per plant and $2 \mathrm{~kg}$ of cow dung per plant induced strongly the development and yield of $J$. curcas and $V$. unguiculata adapted to marginal soils.
\end{abstract}

Key words: Domestication, Jatropha curcas, culture association, production, carbon sequestration, Garoua, Cameroon.

\section{Introduction}

Rural development in the Sudano-Sahelian region of Cameroon relies heavily on cash incomes derived primarily from cotton. The current changes in this sector (competitiveness of cotton fiber on the world market, declining world price of cotton fiber, drastic increase in input costs, etc) and other factors such as declining soil fertility, the irregularity of rainfall and climate change reduce the profitability of cotton at the producer level. The production of "green fuels"

Corresponding author: Tchobsala, research fields: botanic and ecology. including diester is requested to sustain these farmers. $J$. curcas has been recognized to respond to this solicitation. Early studies of botanical and ecological characterization of $J$. curcas in the Sudano-Sahelian region of Cameroon have been initiated in 2007 and 2008 by ESA, in collaboration with the University of Ngaoundere [1]. In 2008 and 2009, research program started in agreement with SODECOTON and IRAD of Garoua, CIRAD and University of Ngaoundere in Kismatari, Garoua, on the agro-ecological characterization of $J$. curcas in a sandy clay soil [2]. The majority of soils in the Sudano-Sahelian zones is characterized by lack of water for both plant growth 

Vigna unguiculata in Marginal Soil of Garoua Region, Cameroon

and nutrient availability, low soil fertility and high temperatures, the water and wind erosion, salinization, compaction, acidification, alkalization, soil crusting and pollution. J. curcas can easily adapt to these types of soils without competing with food crops. It was very important to test the culture of this plant on these soils. The spacing of this association with $V$. unguiculata plant was not yet known, however its association with maize in Honduras and with the sweet potato presented acceptable results [3]. The study aims to characterize the behaviour of J. curcas associated with $V$. unguiculata in marginal soils in the Sahel region in order to improve the livelihoods of the farmers and promote its domestication in rural areas. Specifically, the survey aims to know the performance of the types of establishment (direct seedling and transplanting seedlings set propagator) of J. curcas on degraded land, the impact of different quantities of fertilizers on the parameters of growth, development of $J$. curcas, to assess the yield of J. curcas in combination or not with $V$. unguiculata and carbon sequestration.

\section{Materials and Methods}

\subsection{Description of Study Area}

The study was conducted in Sanguéré-Paul in Bénoué division, land of Garoua Region, in Cameroon. The annual average precipitation is about $900 \mathrm{~mm}$, with a mean monthly temperature ranged between $22-45^{\circ} \mathrm{C}$. The soil is made up of sand and ferrallitic type which characterizes the marginal soils. The vegetation is dominated by shrubs and some trees such as Vitellaria paradoxa, Terminalia glaucescens, Entada africana, etc.

\subsection{Technical and Biological Materials}

Biological materials consisted of seeds of J. curcas and $V$. unguiculata var. lori, from "SICAM". Agricultural materials were Pesticide-General 35 DS (insecticide), Round up Biosec (herbicide), Fertilizer: N-P-K (15-20-15) and dung of cow.
2.2.1 Establishment of Seedlings of J. curcas in Marginal Soils, Cameroon Cleaning and Treatment Ground

The experimental plots were cleared to make a seedling ground clean, with application of Round-up Biosec two weeks before planting at a rate of 8 packets of $260 \mathrm{~g}$ per hectare.

2.2.2 Watering and Germination of J. curcas in Seedbed in Marginal Soils

The figures 1 and 2 presented watering and germination of J. curcas in seedbed. Before the sowing, the board is watered copiously; this allows weeds to grow after two weeks of watering the board is sown in rows or bunches either. For $2 \mathrm{~m}^{2}$, it takes 32 bunches $(8$ $\times 4 \mathrm{~cm}$ ). The seeds were first pretreated with insecticide and seedbed $2 \mathrm{~cm}$ deep and covered with sand to allow uniform emergence. The plates were protected against animals by a fence with thorns. Watering was done every morning. The sowing of the seeds of $J$. curcas on the six boards of propagator was performed in June. A board has a length of $4.5 \mathrm{~m}$ and a width of $2 \mathrm{~m}$. The distance between two plates is $70 \mathrm{~cm}$. Each sheet contains 15 lines, 10 bunch per line and 3 seeds per hill, and spacing is $30 \mathrm{~cm}$ and $20 \mathrm{~cm}$ interpoquet. The surface of the boards is leveled and raked, and the edges to keep water butts for watering. Thus, the floor boards have been sufficiently watered before and after seeding.

2.2.3 Experimental Setup of Direct Seedling and Transplanting in Marginal Soil, Cameroon

The experimental device for setting up trials is the randomized complete block device, four levels of fertilization compared to the control was performed (Table 1). This is F0 $=0 \mathrm{~g} \mathrm{plant}^{-1}, \mathrm{~F} 1=50 \mathrm{~g} \mathrm{plant}^{-1}$, $\mathrm{F} 2=100 \mathrm{~g} \mathrm{plant}^{-1}$ of $15-20-15, \mathrm{~F} 3=1 \mathrm{~kg}$ plant $^{-1}$ and $\mathrm{F} 4=2 \mathrm{~kg}$ plant $^{-1}$ ox dung. Two types of locations were considered. The fertilizer was made in a ring around the plant 15 days after emergence in case of direct seedling, 15 days after the propagator. The culture of $J$. curcas has been associated with $V$. unguiculata $(\mathrm{Cn})$ sown in August which will be compared to the performance of $J$. curcas in pure 


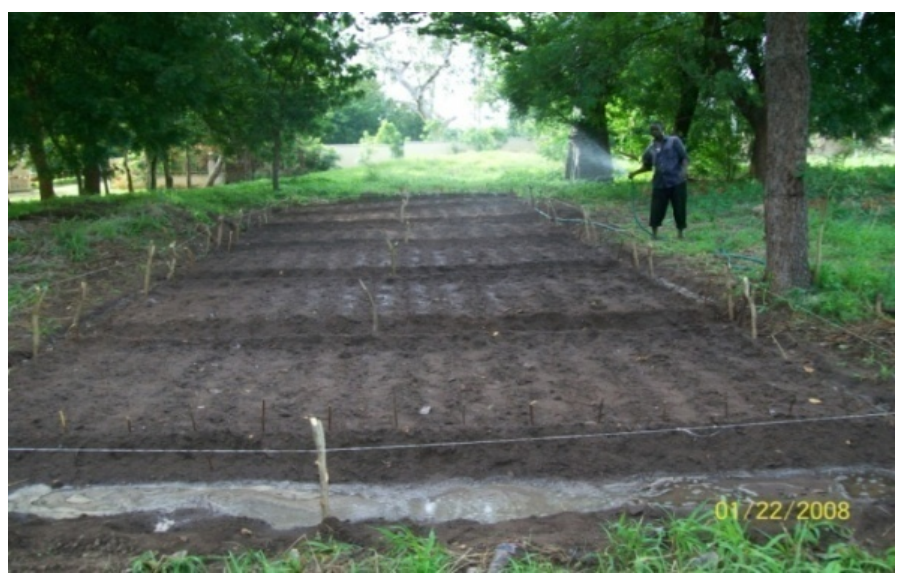

Fig. 1 Watering the seedbed of $J$. curcas seedlings.

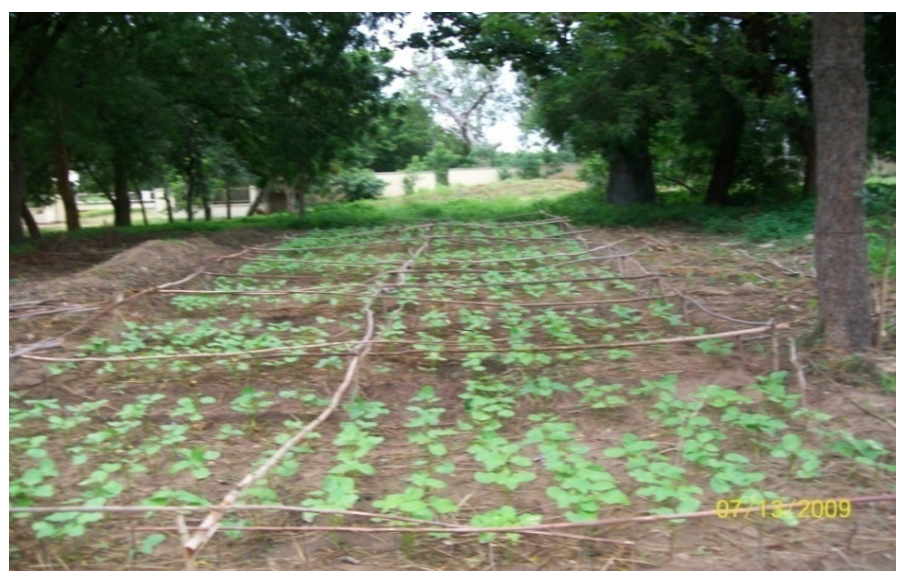

Fig. 2 Germination of $J$. curcas one month after sowing.

Table 1 Plan of the device of the experimental plot of land in marginal soil in Garoua Region of Cameroon.

\begin{tabular}{llllll}
\hline F1SeCn & F4GeP & F0GeP & F4GeCn & F2SeCn & F3GeCn \\
\hline F4GeCn & F1GeCn & F3SeP & F1GeCn & F1SeP & F3GeP \\
\hline F4SeP & F0SeCn & F2SeP & F3SeCn & F0GeCn & F0SeP \\
\hline F1SeP & F3SeP & F2GeCn & F3SeCn & F2GeCn & F2GeP \\
\hline F0SeCn & F0GeP & F3GeP & F0GeCn & F1SeCn & F4GeP \\
\hline F0SeP & F4SeCn & F1GeP & F2SeCn & F4SeP & F4SeCn \\
\hline F1GeCn & F0GeCn & F3GeCn & F1SeCn & F1GeP & F2GeP \\
\hline F3SeCn & F4SeCn & F0SeCn & F0SeP & F2SeP & F2SeCn \\
\hline F2GeP & F2SeP & F4GeP & F4SeP & F1SeP & F3GeCn \\
\hline F4GeCn & F0GeP & F3Se & F1Ge & F2GeCn & F3GeP
\end{tabular}

culture $(\mathrm{P})$ and associated culture. The spacing between lines of $V$. unguiculata is $0.66 \mathrm{~m}$ and between plants of $V$. unguiculata is $30 \mathrm{~cm}$. The trial of $J$. curcas has been installed in 20 elementary plots, 60 plots for three repetitions. Each elementary plot consists of 4 lines $(2+2$ edge useful plants $)$ of 8 plants $(2+6$ central edge useful). The distance between plants is 2 $\mathrm{m}$, between rows of $2 \mathrm{~m}$. The total number of plants is 1.920 seedlings; there were 3.840 seeds. The surface of the elementary plots is $128 \mathrm{~m}^{2}$ (4 rows. $2 \mathrm{~m} .8 .2 \mathrm{~m}$ ). Direct seedling was carried out in July and observations were done on the seedling on August. These observations were made on the two center lines. The transplanting was done in the end of August. 

Vigna unguiculata in Marginal Soil of Garoua Region, Cameroon

Legend: F0GeCn: $0 \mathrm{~g} /$ feet + hotbed + association of culture of $V$. unguiculata; $\mathrm{F} 1 \mathrm{GeCn}$ : $50 \mathrm{~g} /$ feet of 15-22-15 + hotbed + association of culture of $V$. unguiculata; F2GeCn: $100 \mathrm{~g} /$ feet of 15-22-15 + hotbed + association of culture of $V$. unguiculata, F3GeCn: $1 \mathrm{~kg}$ of dung beef/walk + hotbed + combination of culture of $V$. unguiculata; $F 4 \mathrm{GeCn}: 2$ $\mathrm{kg}$ of dung beef/feet + hotbed + combination of culture of $V$. unguiculata; F0SeCn: $0 \mathrm{~g} /$ feet + direct seeding + association culture of $V$. unguiculata; F1SeCn: $50 \mathrm{~g} /$ feet of 15-22-15 + tillcropping $+V$. unguiculata association; F2SeCn: $100 \mathrm{~g} /$ feet of 15-22-15 + till cropping $+V$. unguiculata association; F3SeCn: $1 \mathrm{~kg}$ of dung beef/feet + till cropping + combination of $V$. unguiculata; $\mathrm{F} 4 \mathrm{SeCn}: 2 \mathrm{~kg}$ of dung beef/feet + till cropping + combination of $V$. unguiculata; F0GeP: $0 \mathrm{~g} /$ feet + hotbed + pure culture of J. curas, 4 lines; F1GeP: $50 \mathrm{~g} /$ feet of 15-22-15+ hotbed + pure culture of J. curas; F2GeP: $100 \mathrm{~g}$ /feet of 15-22-15 + hotbed + pure culture of J. curas; F3GeP: $1 \mathrm{~kg}$ of beef dung/feet + hotbed + pure culture of Jatropha curcas; F4GeP: $2 \mathrm{~kg}$ of cattle dung/feet + hotbed + pure culture of $J$. curcas; F0SeP: $0 \mathrm{~g} /$ feet of direct seeding + pure culture + J. curcas; F1SeP: 50 $\mathrm{g} /$ feet of 15-22-15 + direct sowing + pure culture of $J$. curcas; F2SeP: $100 \mathrm{~g} /$ feet of 15-22-15 + direct sowing + pure culture of $J$. Curcas; F3SeP: $1 \mathrm{~kg}$ of dung beef/feet + crop pure of $J$. curcas; F4SeP: $2 \mathrm{~kg}$ of dung beef/feet + direct sowing + pure culture of $J$. curcas.

2.2.4 Establishment of J. curcas in the Field by Direct Seedling in Marginal Soils in Garoua Region

Plowing and clearing land for planting was done in May, with application of Round-up Biosec two weeks before planting at a rate of 8 packets of $260 \mathrm{~g} \mathrm{ha}^{-1}$. Before planting, the plot was pitted, bunches 15.15.15 $\mathrm{cm}^{-3}$ dimension were prepared for the seed of $J$. curcas, 3 seeds processed per hill. There was a distance of $2 \mathrm{~m}$ between rows and 2 feet between plants on line. Thinning was 30 days after sowing. Fertilization is applied in a ring around the plants, five days after singling. Weeding was done three times (20 to 30 days, 90 days and 120 to 130 days after the semi-direct). NPK fertilization was performed 5 days after emergence of the seeds, organic fertilizer, five days after emergence and seed processing plant (fungicides and insecticides), at planting time or before the month of November.

2.2.5 Establishment of J. curcas in the Field by Transplanting in Marginal Soils in Garoua Region of Cameroon

The age of the plants was two months even until they reach a size of 30 to $40 \mathrm{~cm}$ because, from this stage, they begin to develop their offensive odour and no longer likely to be grazed by animals. The field was chosen as flat as possible for transplanting. The soil was light, but not much else the root system would grow too quickly thus preventing transplant, deep and fertile and weeded within a radius of $50 \mathrm{~cm}$ around the plant to prevent pests, it must be moist so does not injure the roots of seedlings, which is removed as seedlings that can be used to replace a missing foot or a new planting. The extractor's nursery stocks in the open, the plates were sprayed the day before to facilitate their removal. The tear was cautious. A ditch was dug across the width of the board deep enough to reach the roots of the plant. Seedlings were subsequently removed one after the other while lifting. Roots were dipped immediately after pulling into a mixture of water, cow dung, clay or earth. The roots were cut to a few centimeters apart from the main root. The plants were transported quickly in the shade and carefully planted in fields and in the immediate holes $30.30 .30 \mathrm{~cm}$ prepared beforehand. We have made well-rotted manure. It was mixed with the soil. Transplanting was done in bed planting hedgerows as soon as the seedlings are large enough to be displaced, that is to say 1 to 2 months after germination. The most appropriate period is late May to early July at the latest. It is very important to note that when conditions are exceptionally favorable for planting, you can lift the plants and dispose of land 
that is attached to the roots. We wrapped the roots of slurry eventually the roots will be briefly immersed in a mixture of water and soil. Seedlings were slipped into the slot, taking care never to bend the roots. To do this, the seedling is lowered to the bottom of the hole and then returned to the collar. Plants too large or too developed were trimmed to reduce transpiration. So first we cut the young leaves and young branches starting from the top, without touching the main stem if it is robust and boots are made of 50 plants that are enclosed in a large polyethylene plastic bag wrapped in wet packaging. Weeding was done as needed, to ensure its own culture, with an initial weeding later than 15 days after emergence, before applying fertilizer.

2.2.6 Technical Culture of J. curcas in Association with $V$. unguiculata in Marginal Soils in Garoua Region of Cameroon

$V$. unguiculata seeds were sown in space between the seedlings of $J$. curcas in August. Two lines of $V$. unguiculata were planted at a density of $60.30 \mathrm{~cm}$.

\subsection{Maintenance of Plants after Transplanting}

It was conducted in two stages: the manual weeding twice in the season and mounding plants at the end of the season for the plants a good resistance to drought.

\subsection{Site Clearing and Direct Seedling of $V$. Unguizculata}

Weeding of the plots was carried out in August. $V$. unguiculata was planted, between rows of J. curcas two lines of $V$. unguiculata were planted at spacing of $60 \mathrm{~cm}$ between rows and $30 \mathrm{~cm}$ in the row of $V$. unguiculata.

\subsection{Observation and Recording of Agronomic}

\section{Parameters}

To assess the development, growth and production of $J$. curcas, the following biometric parameters were recorded once a month from October to January. The various observations are based on botanical surveys in this case plant height, stem diameter at $15 \mathrm{~cm}$ above the ground, the number of branches, number and condition of the leaves, possible attacks, flowering, fruiting, the number of flowers and fruits, the surface of the crown, petiole length, length and width of leaves, branching plants, the state stem, weight of seeds of $J$. curcas, biomass and yield of $V$. unguiculata. To carry out various operations, 14 plants per subplot were randomly selected. We used a caliper to measure the diameter of the plants at a height of $15 \mathrm{~cm}$ from soil. Plant height was measured using a graduated scale from 0 to $2 \mathrm{~m}$; the leaves are always counted as well as male and female flowers. The fruits are also evaluated and the measured diameter. V. unguiculata plants were subject to similar treatment. The number of plants per line was evaluated; the beginning and end of flowering and fruiting were noted.

\subsection{Estimation of Biomass and Carbon Sequestration} of J. Curcas Associated with V. Unguiculata in Marginal Soils

According to Brown, et al. [4], Biomass average = volume average. $0.62 .10^{3}$

Volume average $=\pi \times(D / 2)^{2} . H .0 .5$, where $\mathrm{H}$ is the height average and $\mathrm{D}$ diameter of $J$. curcas, $0.62 .10^{3}$ is the mean wood gravity (Magnésium $\mathrm{m}^{-3}$ ) and 0.5 is the mean form of coefficient of conics trees Carbon sequestration was obtained by biomass. 0.5 according to Henry, et al. [5, 6].

\subsection{Analysis Methods}

The Stat Graphics + and the XLSTAT were used for data analysis.

\section{Results}

\subsection{Seed Germination Boards, Direct Sowing, Survival and Mortality of Seedlings of J. curcas}

The germination (95\%) rate of seeds of $J$. curcas is very important in the third week in the boards (Fig. 3). There are still $5 \%$ of ungerminated seeds in the 


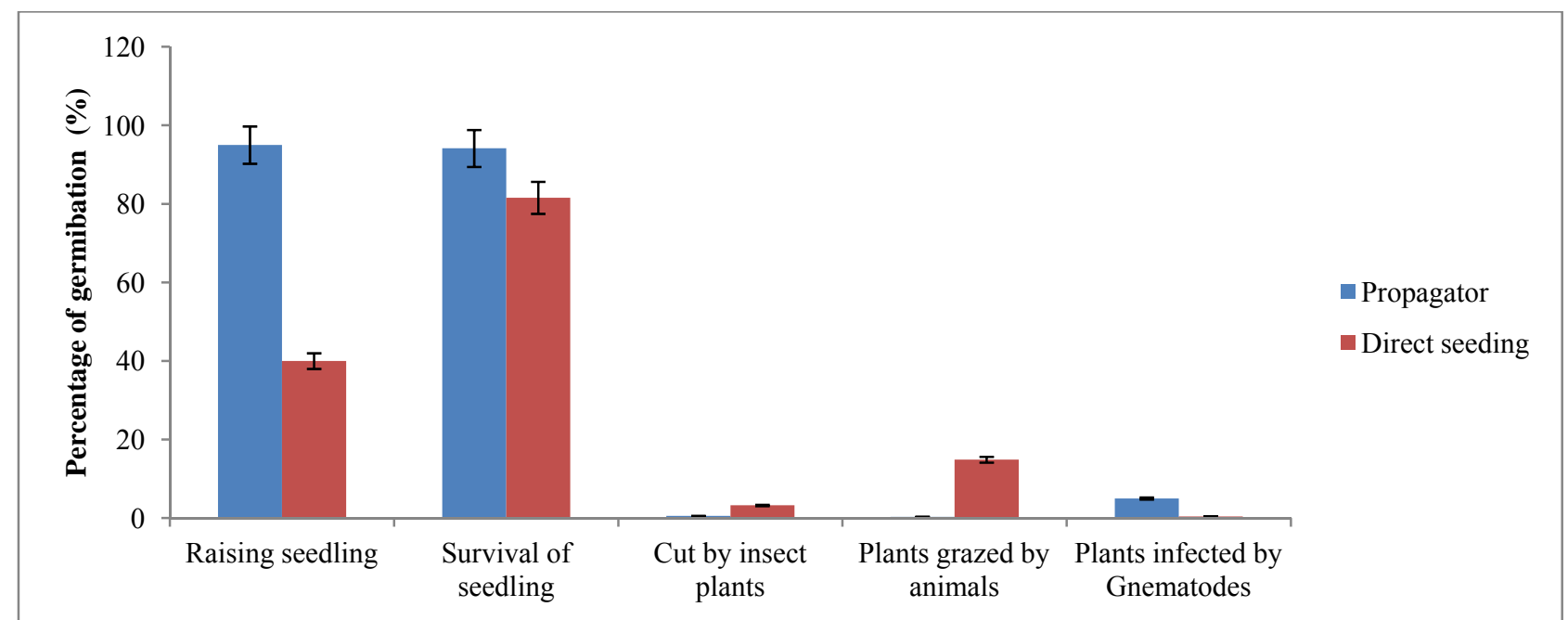

Fig. 3 Percentage of seed germination boards, direct seedling, survival and mortality of seedlings of $J$. curcas (\%) in marginal soils in Garoua Region of Cameroon.

propagator. The germination rate of seeds after direct seedling was $40 \%$ in the third week. This low seed emergence of direct seedling is justified by the scarcity of rainfall and soil type sandy gravel. Once the plants are taken, they are likely to survive without doubt, where the high survival rate observed in the propagator $(94.14 \%)$ and direct sowing $(81.56 \%)$. The mortality of seedlings and direct seedling propagator are usually due to biotic factors such as insects, animals and pests.

3.2 Influence of the Treatment, the Types of Implantation and Association on the Growth and Production of J. curcas in Marginal Soils in Garoua Region of Cameroon

8 parameters of growth and yield were studied (height, diameters, ramification, recover, production and length of the leaves, leaf width and Yield of Seeds of $J$. curcas) (Table 2).

The lower of height of the seedlings of $J$. curcas founded with the treatment F0GeP $(44.50 \pm 7.20 \mathrm{~m})$ and height with F2SeP $(90.14 \pm 2.47 \mathrm{~m})$. This result suggests that the fertilizer with a high dose (F2: $100 \mathrm{~g}$ of NPK) acts strongly on the height growth of seedlings of J. curcas.

The highest diameter $(5.94 \pm 1.00 \mathrm{~cm})$ value is saved with the F1GeP treatment. Between this treatment and treatment $\mathrm{F} 2 \mathrm{SeCn}, \mathrm{F} 4 \mathrm{GeCn}$ and there is a slight difference. Indeed we expect a high diameter of plants with these two treatments because the dose of NPK fertilizer $100 \mathrm{~g} \mathrm{plant}^{-1}, 2 \mathrm{~kg} \mathrm{plant}^{-1}$ and cow dung improve the yield growth of J. curcas. There is a correlation between the length and diameter of $J$. curcas. Both parameters are positively correlated $(P=$ 0.05). During the first two months, they evolve geometrically and then stabilize around the 3rd and 4th month. Growth and development of plants were almost stable because of the cessation of rains. The shape of this curve is valid for all types of treatment.

The average number of branches is highest with treatments $\mathrm{F} 2 \mathrm{SeCn}, \mathrm{F} 2 \mathrm{GeCn}, \mathrm{F} 4 \mathrm{SeP}$ and $\mathrm{F} 4 \mathrm{GeP}$. The dose of NPK $100 \mathrm{~g}$ plant $^{-1}$ and cow dung $2 \mathrm{~kg}$ plant $^{-1}$ improve the number of branches of $J$. curcas in the first year of cultivation in degraded soils. The results showed that J. curcas likes organic and chemical fertilizers for good branching remains low without the addition of these inputs. It should be noted that the branch has a direct implication on the ground covered.

The surface of the crown was evaluated by measuring the covered area by the plant. Treatments F4SeCn has a higher basal area. The lowest values are recorded with the control treatments without the addition of agricultural inputs. There is a problem with leaf coverage and treatment F4SeCn, F2SeP. 

Vigna unguiculata in Marginal Soil of Garoua Region, Cameroon

The production of leaves was important between November and December. $V$. unguiculata is a legume which gives strong production of leaves in December. During the fruiting period of $V$. unguiculata in December, there is a strong release of nitrogen needed for plant nutrition and therefore produce many leaves.

The leaf length of $J$. curcas was important with F0GeCn treatment.

The width of the leaves of J. curcas appears with the treatment $\mathrm{F} 4 \mathrm{SeP}$ and presents a good result as regards the width of leaves. Ox dung to $2 \mathrm{~kg}$ per plant promotes the development of the width of the leaves of $J$. curcas.

The table 3 presented observations, minimum, maximum, mean and standard deviation of 8 parameters of growth and yield of J. curcas. Between the eight parameters, the maximum number of the leaves production $(375,250$ numbers $)$ is important than other parameters.

Table 2 Parameters of growth and yield of $J$. curcas in marginal soils in Garoua Region of Cameroon.

\begin{tabular}{|c|c|c|c|c|c|c|c|c|}
\hline Ttreatmentss & Height (cm) & Diameters $(\mathrm{cm})$ & $\begin{array}{l}\text { Ramification } \\
\text { (number) }\end{array}$ & Recover $\left(\mathrm{m}^{2}\right)$ & $\begin{array}{l}\text { Production of the } \\
\text { leaves (number) }\end{array}$ & $\begin{array}{l}\text { Length of the } \\
\text { leaves }(\mathrm{cm})\end{array}$ & Leaf width (cm) & $\begin{array}{l}\text { Yield of Seeds } \\
\text { of } J . \text { curcas } \\
\left(t h a^{-1}\right)\end{array}$ \\
\hline FoGeCn & $75.83 \pm 10.04 b$ & $2.94 \pm 0.17 \mathrm{ab}$ & $03.735 \pm 0.45 \mathrm{a}$ & $0.14 \pm 0.12 \mathrm{a}$ & $\begin{array}{l}375.25 \pm 562.96 \\
\mathrm{~b}\end{array}$ & $28.19 \pm 21.47 \mathrm{c}$ & $12.79 \pm 9.50 \mathrm{ab}$ & $0.00 \pm 0.00 \mathrm{a}$ \\
\hline FoGeP & $44.50 \pm 7.20 \mathrm{a}$ & $3.78 \pm 0.97 \mathrm{abcd}$ & $07.27 \pm 5.10 \mathrm{ab}$ & $0.12 \pm 0.05 \mathrm{ab}$ & $61.35 \pm 4.42 \mathrm{a}$ & $12.46 \pm 1.04 \mathrm{ab}$ & $14.16 \pm 1.76 \mathrm{bc}$ & $0.94 \pm 0.03 \mathrm{ab}$ \\
\hline FoSeCn & $72.52 \pm 22.80 b$ & $3.78 \pm 0.97 \mathrm{abcd}$ & $06.27 \pm 4.11 \mathrm{ab}$ & $0.04 \pm 0.03 b$ & $61.35 \pm 4.42 \mathrm{a}$ & $12.46 \pm 1.04 \mathrm{ab}$ & $14.16 \pm 1.76 b c$ & $0.15 \pm 0.23 \mathrm{a}$ \\
\hline FoSeP & $71.33 \pm 9.03 b$ & $3.67 \pm 0.36 \mathrm{ab}$ & $05.07 \pm 5.17 \mathrm{ab}$ & $0.15 \pm 0.04 \mathrm{ab}$ & $54.74 \pm 9.95 \mathrm{a}$ & $12.20 \pm 0.87 \mathrm{ab}$ & $12.38 \pm 2.13 \mathrm{ab}$ & $1.19 \pm 1.54 \mathrm{ab}$ \\
\hline $\mathrm{F} 1 \mathrm{GeCn}$ & $74.18 \pm 27.85 b$ & $3.74 \pm 1.01 \mathrm{ab}$ & $07.07 \pm 5.27 \mathrm{ab}$ & $0.37 \pm 0.19 \mathrm{abcd}$ & $112.99 \pm 55.46 \mathrm{a}$ & $11.82 \pm 1.20 \mathrm{ab}$ & $11.57 \pm 1.83 \mathrm{ab}$ & $0.98 \pm 0.56 \mathrm{ab}$ \\
\hline $\mathrm{F} 1 \mathrm{GeP}$ & $69.03 \pm 6.84 \mathrm{~b}$ & $5.94 \pm 1.00 \mathrm{e}$ & $12.78 \pm 0.01 \mathrm{bc}$ & $0.35 \pm 0.56 \mathrm{abcd}$ & $146.64 \pm 11.34 \mathrm{a}$ & $17.99 \pm 10.96 b$ & $13.85 \pm 0.21 \mathrm{abc}$ & $2.55 \pm 1.66 \mathrm{bc}$ \\
\hline $\mathrm{F} 1 \mathrm{SeCn}$ & $77.87 \pm 19.09 b$ & $4.31 \pm 0.38$ bcde & $07.00 \pm 0.02 \mathrm{ab}$ & $0.27 \pm 0.12 \mathrm{abcd}$ & $100.96 \pm 60.92 \mathrm{a}$ & $11.60 \pm 1.38 \mathrm{ab}$ & $12.72 \pm 2.42 \mathrm{ab}$ & $3.01 \pm 2.67 \mathrm{bc}$ \\
\hline $\mathrm{F} 1 \mathrm{SeP}$ & $77.87 \pm 19.09 b$ & $4.31 \pm 0.38$ bcde & $08.00 \pm 0.01 \mathrm{ab}$ & $0.31 \pm 0.26 \mathrm{abcd}$ & $100.96 \pm 60.92 \mathrm{a}$ & $11.60 \pm 1.38 \mathrm{ab}$ & $12.72 \pm 2.42 \mathrm{ab}$ & $3.46 \pm 3.02 b c$ \\
\hline $\mathrm{F} 2 \mathrm{GeCn}$ & $73.40 \pm 9.38 b$ & $4.79 \pm 0.50 \mathrm{de}$ & $103.46 \pm 0.01 \mathrm{c}$ & $0.31 \pm 0.04 \mathrm{bcd}$ & $98.86 \pm 42.65 \mathrm{a}$ & $11.18 \pm 0.79 \mathrm{ab}$ & $12.71 \pm 2.17 \mathrm{ab}$ & $0.58 \pm 0.32 \mathrm{ab}$ \\
\hline $\mathrm{F} 2 \mathrm{GeP}$ & $80.16 \pm 4.36 b$ & $4.78 \pm 1.15 \mathrm{cde}$ & $02.53 \pm 0.02 \mathrm{a}$ & $0.39 \pm 0.03 \mathrm{abcd}$ & $125.84 \pm 44.62 \mathrm{a}$ & $9.63 \pm 0.93 \mathrm{ab}$ & $10.99 \pm 0.93 \mathrm{a}$ & $0.86 \pm 0.54 \mathrm{ab}$ \\
\hline $\mathrm{F} 2 \mathrm{SeCn}$ & $73.40 \pm 9.38 b$ & $4.99 \pm 0.50 \mathrm{de}$ & $13.96 \pm 8.72 \mathrm{c}$ & $0.29 \pm 0.15 \mathrm{abcd}$ & $98.86 \pm 42.65 \mathrm{a}$ & $11.18 \pm 0.79 \mathrm{ab}$ & $12.71 \pm 2.17 \mathrm{ab}$ & $1.84 \pm 1.05 \mathrm{ab}$ \\
\hline $\mathrm{F} 2 \mathrm{SeP}$ & $90.14 \pm 2.47 b$ & $4.61 \pm 0.18$ bcde & $09.48 \pm 0.39 \mathrm{ab}$ & $0.49 \pm 0.20 \mathrm{~cd}$ & $111.70 \pm 1.21 \mathrm{a}$ & $10.40 \pm 1.85 \mathrm{ab}$ & $11.30 \pm 1.23 \mathrm{a}$ & $4.07 \pm 3.14 \mathrm{c}$ \\
\hline F3GeCn. & $73.43 \pm 6.37 b$ & $4.20 \pm 0.54$ bcde & $10.17 \pm 6.46$ & $0.26 \pm 0.09 \mathrm{abcd}$ & $101.57 \pm 11.97 \mathrm{a}$ & $9.31 \pm 0.79 \mathrm{ab}$ & $10.54 \pm 1.05 \mathrm{a}$ & $0.15 \pm 0.12 \mathrm{a}$ \\
\hline F3GeP & $79.66 \pm 10.46 b$ & $4.04 \pm 0.34$ bcde & $09.57 \pm 2.69 \mathrm{ab}$ & $0.42 \pm 0.22 \mathrm{abcd}$ & $106.33 \pm 16.75 \mathrm{a}$ & $10.38 \pm 2.80 \mathrm{ab}$ & $12.14 \pm 2.43 \mathrm{ab}$ & $0.98 \pm 0.67 \mathrm{ab}$ \\
\hline $\mathrm{F} 3 \mathrm{SeCn}$ & $66.94 \pm 20.77 \mathrm{ab}$ & $3.79 \pm 054 \mathrm{abcd}$ & $11.80 \pm 0.01 \mathrm{bc}$ & $0.18 \pm 0.10 \mathrm{abc}$ & $80.96 \pm 13.25 \mathrm{a}$ & $9.35 \pm 0.30 \mathrm{ab}$ & $10.93 \pm 0.16 \mathrm{a}$ & $0.40 \pm 0.12 \mathrm{a}$ \\
\hline F3SeP & $67.37 \pm 14.87 \mathrm{ab}$ & $3.91 \pm 0.34 \mathrm{abcd}$ & $12.36 \pm 1.62 \mathrm{bc}$ & $0.22 \pm 0.16 \mathrm{abcd}$ & $52.73 \pm 40.07 \mathrm{a}$ & $9.94 \pm 1.45 \mathrm{ab}$ & $12.93 \pm 1.53 \mathrm{ab}$ & $0.06 \pm 0.01 \mathrm{a}$ \\
\hline $\mathrm{F} 4 \mathrm{GeCn}$ & $66.45 \pm 13.42 \mathrm{ab}$ & $4.97 \pm 0.26$ abcé & $05.20 \pm 5.84 \mathrm{a}$ & $0.40 \pm 0.29 \mathrm{abcd}$ & $114.19 \pm 27.55 \mathrm{a}$ & $9.17 \pm 0.62 \mathrm{ab}$ & $12.13 \pm 0.69 \mathrm{a}$ & $0.04 \pm 0.12 \mathrm{a}$ \\
\hline $\mathrm{F} 4 \mathrm{GeP}$ & $72.52 \pm 22.80 \mathrm{~b}$ & $3.97 \pm 0.54 \mathrm{bcd}$ & $11.27 \pm 2.55 b c$ & $0.53 \pm 0.09 \mathrm{~d}$ & $98.90 \pm 21.63 \mathrm{a}$ & $8.79 \pm 0.57 \mathrm{a}$ & $9.96 \pm 1.10 \mathrm{a}$ & $1.00 \pm 0.43 \mathrm{ab}$ \\
\hline $\mathrm{F} 4 \mathrm{SeCn}$ & $76.45 \pm 3.96 b$ & $3.88 \pm 0.11 \mathrm{abcd}$ & $08.89 \pm 7.94 \mathrm{ab}$ & $0.32 \pm 0.25 \mathrm{abcd}$ & $95.28 \pm 14.51 \mathrm{a}$ & $9.34 \pm 0.80 \mathrm{ab}$ & $10.31 \pm 0.87 \mathrm{a}$ & $0.83 \pm 0.14 \mathrm{ab}$ \\
\hline F4SeP & $75.83 \pm 10.04 b$ & $3.93 \pm 0.34 \mathrm{abcd}$ & $13.07 \pm 0.66 \mathrm{c}$ & $0.30 \pm 0.08 \mathrm{abcd}$ & $103.87 \pm 29.42 \mathrm{a}$ & $10.36 \pm 7.31 \mathrm{ab}$ & $16.41 \pm 0.71 \mathrm{c}$ & $2.15 \pm 1.24 b c$ \\
\hline
\end{tabular}

Values in the same line followed with different letters in superscript are significantly different at $P<0.05$.

Table 3 Observations, minimum, maximum, mean and standard deviation of dendrometrics and yield of seed of $J$. curcas.

\begin{tabular}{lllll}
\hline Variable & Minimum & Maximum & Mean & Standard deviation \\
\hline Height $(\mathrm{cm})$ & 44.50 & 90.14 & 72.94 & 08.61 \\
Diameters (cm) & 02.94 & 05.94 & 04.22 & 00.65 \\
Ramification (number) & 02.53 & 103.40 & 13.45 & 21.42 \\
Recover (m ${ }^{2}$ ) & 00.04 & 90.53 & 00.29 & 00.13 \\
Production of the leaves (number) & 52.73 & 375.25 & 110.16 & 66.79 \\
Length of the leaves (cm) & 08.79 & 28.19 & 11.87 & 04.34 \\
Leaf width (cm) & 09.96 & 16.41 & 12.37 & 01.54 \\
Yield of Seeds of J. curcas (t.ha $\left.{ }^{-1}\right)$ & 00.00 & 4.07 & 01.26 & 01.20
\end{tabular}


3.3 Matrices of Pearson (n) Correlation of the Types of Implantation and Association on the Growth and Production of J. Curcas in Marginal Soils in Garoua Region of Cameroon

There was important correlation between the production of the leaves and the length of the leaves $(\mathrm{R}$ $=0.861 ; P \geq 0.001$ ) (Table 4). The Principal Component Analysis (PCA) of the parameters of growths and yield of $J$. curcas in marginal soils in Garoua Region of Cameroon showed that these parameters were correlated with the Biplot (F1 and F2 ) to $53.24 \%$. It was opposed to the positives and imperfect correlation between the height and the recover parameters $(\mathrm{R}=0.486 ; P \leq 0.5)$. There was negative correlation between the yield of seeds and the ramification $(\mathrm{R}=-0.097)$ of $J$. curcas in marginal soils in Garoua Region of Cameroon (Fig. 4). According to the treatments, F2SeP and FoGeCn were positively correlated with Biplot (axis F1 and F2: $53.24 \%$ ), while the treatments FoGeP, F3SeP, F3SeCn, FoSeP and FoSeCn were negatively correlated with F1 (30.63\%) axis.

3.4 Dendrogramm of the Parameters of Growth and Yield of J. curcas in Marginal Soils in Garoua Region of Cameroon

Figure 5 presented the dendrogramm parameters of growth and yield of $J$. curcas in marginal soils in

Table 4 Matrices of Pearson (n) correlation of the types of implantation and association on the growth and production of $J$. curcas in marginal soils in Garoua Region of Cameroon.

\begin{tabular}{lllllllll}
\hline Variables & $\begin{array}{l}\text { Height } \\
(\mathrm{cm})\end{array}$ & $\begin{array}{l}\text { Diameters } \\
(\mathrm{cm})\end{array}$ & $\begin{array}{l}\text { Rami } \\
\text { fication }\end{array}$ & $\begin{array}{l}\text { Recover } \\
\left(\mathrm{m}^{2}\right)\end{array}$ & $\begin{array}{l}\text { Production } \\
\text { of the } \\
\text { leaves }\end{array}$ & $\begin{array}{l}\text { Length of } \\
\text { the leaves } \\
(\mathrm{cm})\end{array}$ & $\begin{array}{l}\text { Leaf width } \\
(\mathrm{cm})\end{array}$ & $\begin{array}{l}\text { Yield of } \\
\text { Seeds } \\
\left(\mathrm{t} \mathrm{ha}^{-1}\right)\end{array}$ \\
\hline Height & 1 & 0.104 & 0.006 & 0.486 & 0.232 & -0.027 & -0.284 & 0.427 \\
Diameters & 0.104 & 1 & 0.248 & 0.463 & -0.203 & -0.220 & 0.032 & 0.388 \\
Ramification & 0.006 & 0.248 & 1 & 0.061 & -0.087 & -0.079 & 0.073 & -0.097 \\
Recover & 0.486 & 0.463 & 0.061 & 1 & -0.020 & -0.362 & -0.440 & 0.376 \\
Production of the leaves & 0.232 & -0.203 & -0.087 & -0.020 & 1 & 0.861 & 0.004 & -0.097 \\
Length of the leaves & -0.027 & -0.220 & -0.079 & -0.362 & 0.861 & 1 & 0.290 & -0.062 \\
Leaf width & -0.284 & 0.032 & 0.073 & -0.440 & 0.004 & 0.290 & 1 & 0.170 \\
Yield of Seeds of J. curcas & 0.427 & 0.388 & -0.097 & 0.376 & -0.097 & -0.062 & 0.170 & 1 \\
\hline
\end{tabular}

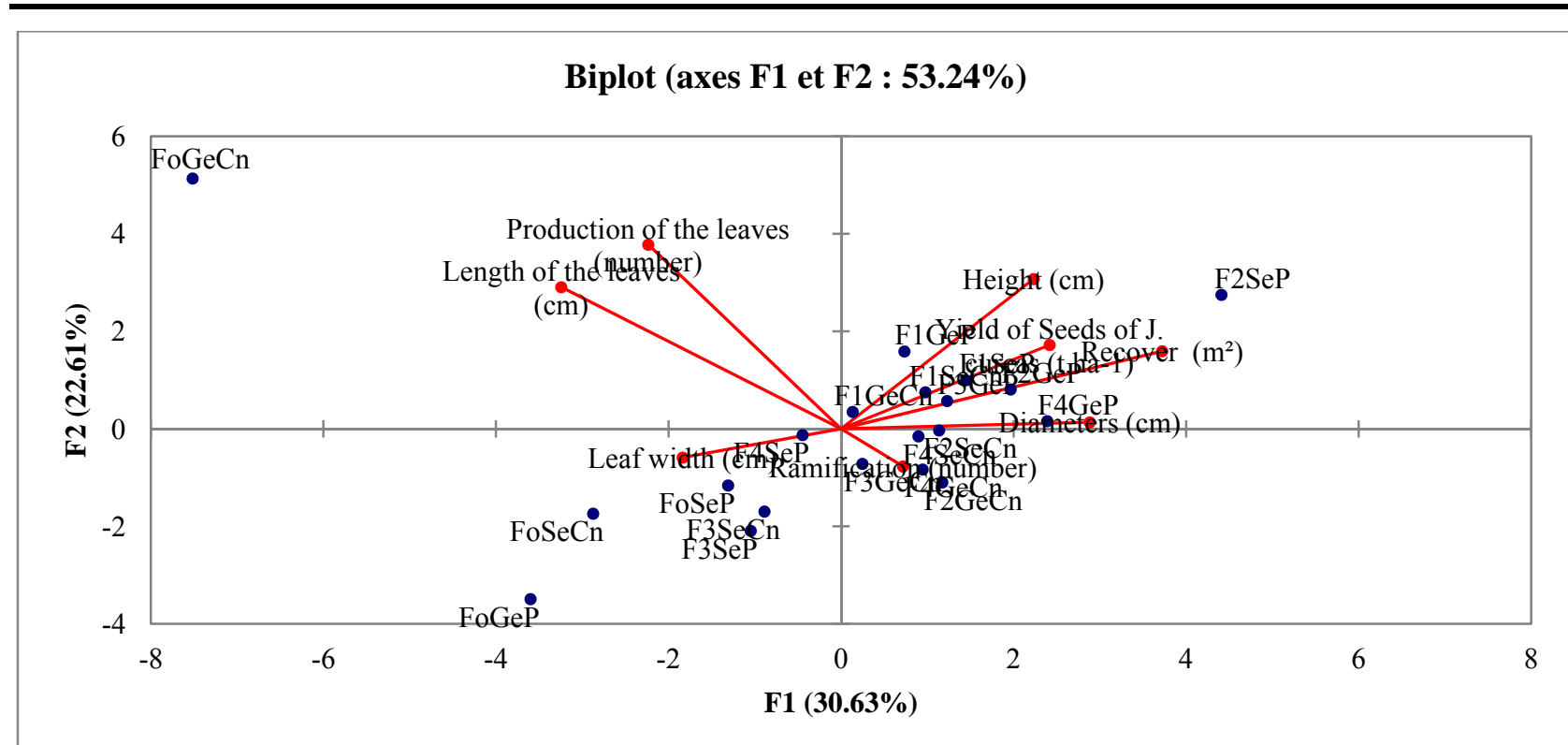

Fig. 4 Principal Component Analysis (PCA) of the parameters of growth and yield of $J$. curcas in marginal soils in Garoua Region of Cameroon. 

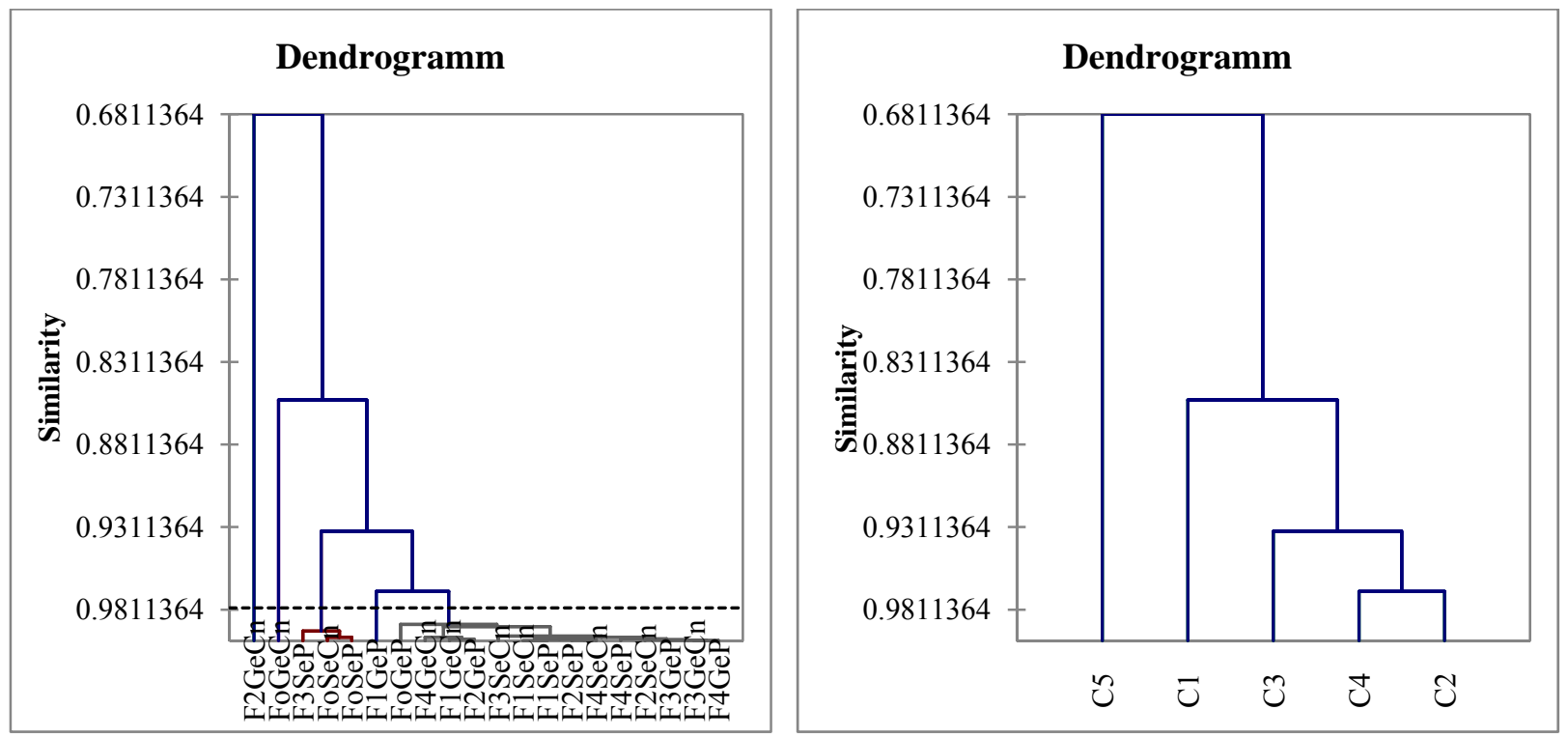

Fig. 5 Dendrogramm of parameters of growth and yield of $J$. curcas in marginal soils in Garoua Region of Cameroon.

Garoua Region of Cameroon. The different treatments were grouped in five classes: Class 1 with one treatment (FoGeCn); Class 2 with 14 treatments (FoGeP, F1GeCn, F1SeCn, F1SeP, F2GeP, F2SeCn, F2SeP, F3GeCn, F3GeP, F3SeCn, F4GeCn, F4GeP, F4SeCn, F4SeP); class 3 with treatments (FoSeCn, FoSeP, F3SeP); class 4 with one treatment (F1GeP) and class 5 with one treatment $(\mathrm{F} 2 \mathrm{GeCn})$. Each group had the same characteristics and similarities parameters.

\subsection{Distance between Centers Objects of the} Treatment of J. curcas in Marginal Soils in Garoua Region of Cameroon

The distance between centers objects was presented in this table 5. The higher distances were observed between class 1 (FoGeCn) and class 3 (FoSeP) $(320.946 \mathrm{~cm})$ and class one $(\mathrm{FoGeCn})$ and class five (F2GeCn) $(294.32 \mathrm{~cm})$.

3.6 Barycenters of Classes of the Parameters of Growths and Yield of J. curcas in Marginal Soils in Garoua Region of Cameroon

The table 6 presented the barycenter of classes of the parameters of growths and yield of $J$. curcas in marginal soils in Garoua Region of Cameroon. It was important in class one with (FoGeCn) $(375.25 \mathrm{~cm})$ treatment and class $5(146.64 \mathrm{~cm})$ with production of the leaves. The yield of seeds of $J$. curcas $\left(2.55 \mathrm{t} \mathrm{ha}^{-1}\right)$ was important with the F1GeP treatment in the 4 class. While the Recover $\left(0.35 \mathrm{~m}^{2}\right)$ is important in the 4 classes with F1GeP treatment.

3.7 Weight, Distance, Inertia of the Treatments of J. curcas in Marginal Soils in Garoua Region of Cameroon

The AFC analysis (Table 7) presented the weight, distance, inertia of the parameters of growth and yield of $J$. curcas in marginal soils in Garoua Region of Cameroon. The treatment $\mathrm{F} 2 \mathrm{GeCn}$ showed that the relative weight (1.18); the distance (1.40), Inertia (0.09) and relative Inertia $(0.07)$ were important than the other treatments.

3.8 Weight, Distances and Quadratic Distances at the Origin and Relative Inertia of the Parameters of Growths and Yield of J. curcas in Marginal Soils

The table 8 presented the weight, distances and quadratic distances, inertia and relative inertia of fruit yield and seeds of $J$. curcas in marginal soils in Garoua Region of Cameroon. The production of the leaves $(0.49)$ and height $(0.32 \mathrm{~cm})$ had the important 
Table 5 Distance between centers objects of the treatments of growths and yield of $J$. curcas in marginal soils in Garoua Region of Cameroon.

\begin{tabular}{llllll}
\hline Treatments & $1(\mathrm{FoGeCn})$ & $2(\mathrm{~F} 3 \mathrm{GeCn})$ & $3(\mathrm{FoSeP})$ & $4(\mathrm{~F} 1 \mathrm{GeP})$ & $5(\mathrm{~F} 2 \mathrm{GeCn})$ \\
\hline $1(\mathrm{FoGeCn})$ & 0 & 274.43 & 320.95 & 229.15 & 294.32 \\
$2(\mathrm{~F} 3 \mathrm{GeCn})$ & 274.43 & 0 & 47.29 & 46.40 & 93.32 \\
$3(\mathrm{FoSeP})$ & 320.95 & 47.29 & 0 & 92.48 & 107.81 \\
$4(\mathrm{~F} 1 \mathrm{GeP})$ & 229.15 & 46.40 & 92.48 & 0 & 102.80 \\
$5(\mathrm{~F} 2 \mathrm{GeCn})$ & 294.32 & 93.32 & 107.81 & 102.80 & 0 \\
\hline
\end{tabular}

Table 6 Barycenter of classes of the parameters of growths and yield of $\boldsymbol{J}$. curcas in marginal soils in Garoua Region of Cameroon.

\begin{tabular}{lllllllll}
\hline Classe & $\begin{array}{l}\text { Height } \\
(\mathrm{cm})\end{array}$ & $\begin{array}{l}\text { Diameters } \\
(\mathrm{cm})\end{array}$ & Ramification $\begin{array}{l}\text { Recover } \\
\left(\mathrm{m}^{2}\right)\end{array}$ & $\begin{array}{l}\text { Production } \\
\text { of the leaves }\end{array}$ & $\begin{array}{l}\text { Length of } \\
\text { the leaves } \\
(\mathrm{cm})\end{array}$ & $\begin{array}{l}\text { Leaf width } \\
(\mathrm{cm})\end{array}$ & $\begin{array}{l}\text { Yield of Seeds of } J . \\
\text { curcas }(\mathrm{t} \text { ha }\end{array}$ \\
\hline $1(\mathrm{FoGeCn})$ & 75.83 & 2.94 & 4 & 0.140 & 375 & 28.19 & 12.79 & 0.00 \\
$2(\mathrm{~F} 3 \mathrm{GeCn})$ & 73.43 & 4.20 & 10 & 0.260 & 102 & 9.31 & 10.54 & 0.15 \\
$3(\mathrm{FoSeP})$ & 71.33 & 3.67 & 5 & 0.150 & 55 & 12.20 & 12.38 & 1.19 \\
$4(\mathrm{~F} 1 \mathrm{GeP})$ & 69.03 & 5.94 & 13 & 0.350 & 147 & 17.99 & 13.85 & 2.55 \\
$5(\mathrm{~F} 2 \mathrm{GeCn})$ & 73.40 & 4.79 & 103 & 0.310 & 99 & 11.18 & 12.71 & 0.58 \\
\hline
\end{tabular}

Table 7 Weight, distance, inertia of treatments of $\mathbf{J}$. curcas in marginal soils in Garoua Region of Cameroon.

\begin{tabular}{llllllll}
\hline Treatments & Weight & Distance & Inertia & Treatments & Weight & Distance & Inertia (relative) \\
\hline FoGeCn & 0.110 & 0.558 & 0.216 & F2GeP & 0.052 & 0.224 & 0.017 \\
FoGeP & 0.032 & 0.264 & 0.014 & F2SeCn & 0.048 & 0.078 & 0.002 \\
FoSeCn & 0.038 & 0.321 & 0.024 & F2SeP & 0.053 & 0.205 & 0.014 \\
FoSeP & 0.035 & 0.352 & 0.028 & F3GeCn & 0.046 & 0.102 & 0.003 \\
F1GeCn & 0.049 & 0.122 & 0.005 & F3GeP & 0.049 & 0.099 & 0.003 \\
F1GeP & 0.059 & 0.174 & 0.011 & F3SeCn & 0.041 & 0.114 & 0.003 \\
F1SeCn & 0.048 & 0.173 & 0.009 & F3SeP & 0.035 & 0.329 & 0.024 \\
F1SeP & 0.048 & 0.181 & 0.010 & F4GeCn & 0.047 & 0.186 & 0.010 \\
F2GeCn & 0.067 & 1.184 & 0.596 & F4GeP & 0.046 & 0.084 & 0.002 \\
\hline
\end{tabular}

Table 8 Weight, distances and quadratic distances, inertia and relative inertia of the parameters of growth and yield of $J$. curcas in marginal soils in Garoua Region of Cameroon.

\begin{tabular}{lllll}
\hline & Relative weight & Distance & Distance $^{2}$ & Relative inertia \\
\hline Height $(\mathrm{cm})$ & 0.322 & 0.236 & 0.056 & 0.113 \\
Diameters $(\mathrm{cm})$ & 0.019 & 0.274 & 0.075 & 0.009 \\
Ramification (number) & 0.059 & 1.301 & 1.692 & 0.634 \\
Recover $\left(\mathrm{m}^{2}\right)$ & 0.001 & 0.444 & 0.197 & 0.002 \\
Production of the leaves (number) & 0.486 & 0.231 & 0.054 & 0.164 \\
Length of the leaves (cm) & 0.052 & 0.222 & 0.049 & 0.016 \\
Leaf width (cm) & 0.055 & 0.299 & 0.090 & 0.031 \\
Yield of Seeds of J. curcas $\left(\mathrm{t} \mathrm{ha}^{-1}\right)$ & 0.006 & 0.929 & 0.863 & 0.030 \\
\hline
\end{tabular}

relative weight, while ramification (1.301), relative inertia (0.634) had the very important values.

3.9 Yield of Fruit and Seeds of J. curcas in Marginal Soils in Garoua Region of Cameroon

The random selection of one foot of $J$. curcas fruiting in December showed that the average diameter ranges from 5 to $8.5 \mathrm{~cm}$ and $J$. curcas can produce 3 to 4 fruit during the first year that the plant is well protected. The number of fruit and seed yield of $J$. curcas is zero with the control treatment .The treatment F2SeP has a good yield in seed weight. This 
result shows that the $50 \mathrm{~g}$ NPK plant ${ }^{-1}$ stimulates growth fruits production and seed yield of J. curcas. In December the plants in general and those having undergone treatments F2 and F4 in particular have produced 2-6 fruits (Fig. 4).

3.10 Mixed Cultivation of J. curcas and V. unguiculata in Marginal Soils in Garoua Region of Cameroon

Figure 6 illustrates the combination of $J$. curcas and $V$. unguiculata (1 ligne of J. curcas $+2 \mathrm{~V}$. unguiculata lines +1 line of $J$. curcas etc.). This mixing has a good performance of the production of biomass of both plants. The production of $V$. unguiculata is in a state of maturity and is ready to be harvested in November.

3.11 Production of Biomass, Sequestration of Carbon and Yield of V. unguiculata Associated with J. curcas in Marginal Soils in Garoua Region of Cameroon

F4GeCn treatment has a good production of biomass with $V$. unguiculata $\left(2.27 \pm 1.22 \mathrm{t} \mathrm{ha}^{-1}\right)$ and yield $\left(154.62 \mathrm{t} \mathrm{ha}^{-1}\right)$ (Table 9). This result shows that the dose of $2 \mathrm{~kg}$ of cow dung associated with the propagator technique improves the culture of J. curcas associated with $V$. unguiculata. The witness (F0GeCn) with the propagator technique has a low biomass (1.64 $\left.\mathrm{t} \mathrm{ha}^{-1}\right)$ and low seed yield of $V$. unguiculata $(161.74 \mathrm{t}$ $\mathrm{ha}^{-1}$ ) in combination with $J$. curcas. Sequestration of carbon was correlated with a production of biomass of $V$. unguiculata and J. curcas associed.

\section{Discussion}

4.1 Germination of Seeds of J. curcas by Propagator and Direct Seedling

Germination rate of seeds in the seedbed is greater than the direct seedling for several reasons. The seeds were treated well and the plates were well watered. Protection boards against insects, pests and predators have promoted a very high rate of emergence of seeds.

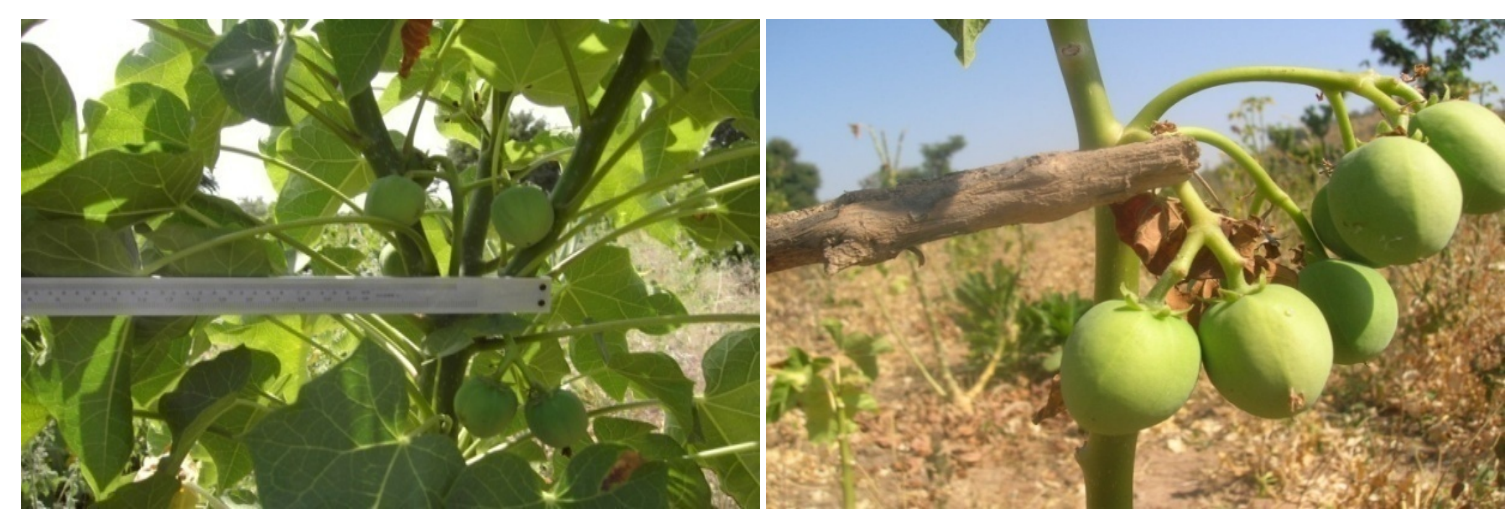

Fig. 4 Overview of the fruits of $J$. curcas L. in marginal soils in Garoua Region of Cameroon.

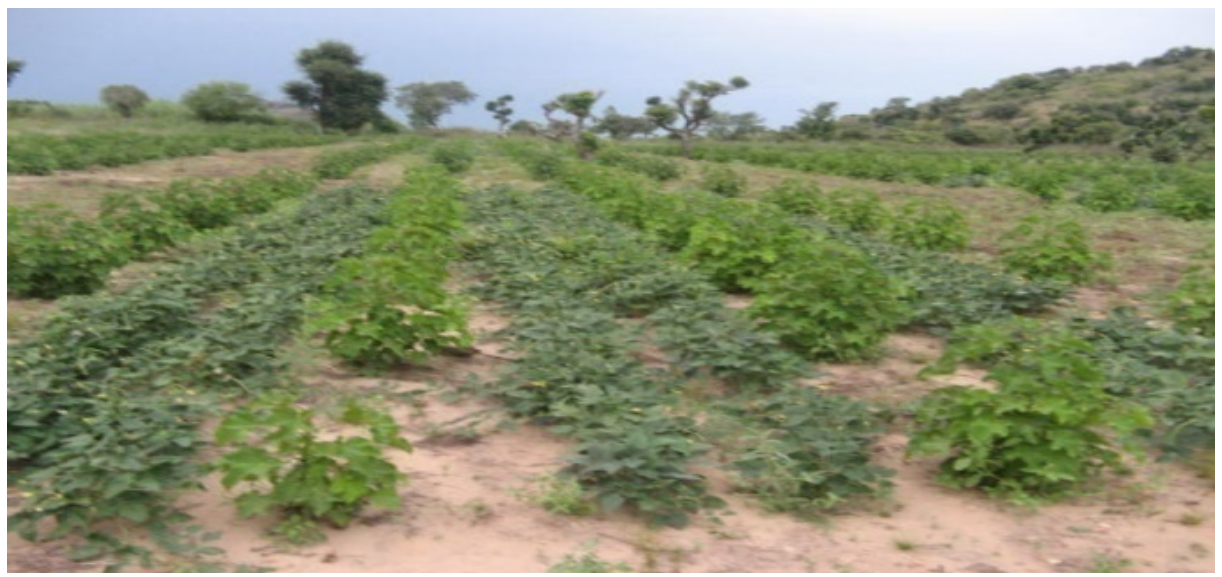

Fig. 5 Mixed cultivation of $J$. curcas and V. unguiculata in the marginal soil of Garoua Region of Cameroon. 
Table 9 Production of biomass, sequestration of Carbon and yield of $V$. unguiculata and $J$. curcas associated in marginal soils in Garoua Region of Cameroon.

\begin{tabular}{lllllll}
\hline Traitement & $\begin{array}{l}\text { Biomass of } V . \\
\text { unguiculata } \\
\left(\mathrm{t} \mathrm{ha}^{-1}\right)\end{array}$ & $\begin{array}{l}\text { Biomass of } J . \\
\text { curcas } \\
\left(\mathrm{t} \mathrm{ha}^{-1}\right)\end{array}$ & $\begin{array}{l}\text { Sequestration } \\
\text { of Carbon } V . \\
\text { unguiculata } \\
(\mathrm{tCha}-1)\end{array}$ & $\begin{array}{l}\text { Sequestration of } \\
\text { Carbon of of } J . \\
\text { curcas } \\
(\mathrm{tCha}-1)\end{array}$ & $\begin{array}{l}\text { Yield of } V . \\
\text { unguiculata } \\
\left(\mathrm{t} \mathrm{ha}^{-1}\right)\end{array}$ & $\begin{array}{l}\text { Yield of Seeds of } \\
J . \text { curcas } \\
\left(\mathrm{t} \mathrm{ha}^{-1}\right)\end{array}$ \\
\hline F0GeCn & 1.64 & 61.74 & 0.82 & 30.87 & 1.17 & 0.00 \\
F0SeCn & 1.88 & 97.61 & 0.94 & 48.81 & 1.33 & 0.15 \\
F1GeCn & 1.95 & 97.74 & 0.98 & 48.87 & 1.23 & 0.98 \\
F1SeCn & 2.11 & 136.26 & 1.06 & 68.13 & 1.25 & 3.01 \\
F2GeCn & 1.88 & 158.64 & 0.94 & 79.32 & 1.37 & 0.58 \\
F2SeCn & 1.80 & 172.17 & 0.90 & 86.09 & 1.21 & 1.84 \\
F3GeCn & 1.95 & 122.02 & 0.98 & 61.01 & 1.25 & 0.15 \\
F3SeCn & 1.99 & 90.58 & 1.00 & 45.29 & 1.41 & 0.40 \\
F4GeCn & 2.27 & 154.62 & 1.14 & 77.31 & 1.60 & 0.04 \\
F4SeCn & 2.07 & 108.42 & 1.04 & 54.21 & 1.43 & 0.83 \\
\hline
\end{tabular}

If the rate of germination of seeds of $J$. curcas is low with direct seedling, it is due to several factors such as grain size state seed (purity, presence of germs, high germination) and the selection of seeds from the last harvest [7]. However, the conditions and sources of seed of J. curcas which we were given by ESA Ngong have not met all these conditions. So that the rate of germination of seeds of $J$. curcas is very low in the first week according to two techniques of seedling. It is for this reason that we replant seeds of J. curcas three times to get the satisfactory result to the third week. Aruna, et al. [8] obtained a germination rate of seeds of $86 \% 15$ days after sowing and [9] has been completely observed the germination of J. curcas 9 days after planting. The depth of seasons and climatics conditions influences the rate of germination of seeds of J. curcas. The shallow planting may be more favorable because germs are using less energy to lift the ground. To ensure good germination, it is recommended to dig holes $20 \mathrm{~cm}$ in radius to fill the holes slightly with soil, to plant 2-3 seeds per hole. These seeds should be equidistant from each other in the hole with a gap of $10 \mathrm{~cm}$ minimum. This shows that climatic factors influence the rate of germination. Other significant factors such as biotic (partridges and ants that dig up the seeds) contribute to the reduction in germination of seeds of $J$. curcas. The direct seeding was done in late July or maintained the period till the end of June with regular watering of seeds and seedlings to the permanent rain. The dimensions of transplanting are $30.30 .30 \mathrm{~cm}$ and several authors had shown that these holes could vary from 30. 30. 30 $\mathrm{cm}$ to $40.40 .40 \mathrm{~cm}$. These holes could be filled with soil surface. At this time, the sap flows from the trunk after incision. It is advised to stop irrigation 2-3 weeks before the removal of seedlings for transplanting on the final site. Transplanting takes place at the beginning of the rainy season. However if supplementary irrigation is possible the author recommends a transplant shortly before the start of the rainy season. This allows time of work early rainy season and gives the plants more time to grow and withstand a drought. If planting is done before the start of the rainy season and no irrigation is possible, it is possible to reduce evaporation by placing three stones around the plant or by other methods such as mulching or plastic mulch.

\subsection{Comparison of Survival Rate of Seedlings for Each Planting Method}

Similar results on the survival rate of plants by various methods have been found in Senegal [10]. The survival rate lowest are those obtained under no-tillage between 5 and 50\% with an annual average of $19.8 \%$. According to this author, the rate depends not only on the sowing date and sowing depth but also 

Vigna unguiculata in Marginal Soil of Garoua Region, Cameroon

the test year. The tests confirmed that the planting should be done after the start of the rainy season. For nursery seedlings, survival rates range from 79 to $100 \%$.

\subsection{Influence of the Parameters of Fertilizers on Production and Yield of J. curcas}

The fertilizer $100 \mathrm{~g}$ of NPK per plant and $2 \mathrm{~kg}$ to cow dung per plant. J. curcas plants have very important ramifications in Sanguéré-Paul with an average of 10 branches per plant. We found that the early branch of the plant has a decisive effect on the yield of J. curcas as inflorescences developed only the tips of a longer branches and it would produce important fruit. The branching is well correlated with yield. In India, Patolia [11] noted a positive correlation between seed yield and number of tertiary branches per plant and to a lesser extent a positive correlation between yield and number of secondary branches per plant. The branching is well correlated with yield. It is found that strong chemical and organic fertilizers promote increased yields. Many authors support these findings. Among them we cite the work of [12] at Patancheru in India who have made $100 \mathrm{~g}$ urea and $38 \mathrm{~g}$ of superphosphate per plant at planting. 21 months after planting (density not specified), the number of branches per plant was 3.8 branches for control and 8.7 for plants receiving fertilizer. The plant height is greater to $60 \mathrm{~cm}$ on average for fertilized plants and less than $60 \mathrm{~cm}$ for plants not fertilized. Similarly study conducted by [13] encourages a mixture of surface soil with $0.5 \mathrm{~kg}$ of superphosphate and application of $250 \mathrm{~g}$ NPK (15-15-15) per plant at the beginning of the wet season from the second year. The yield of $J$. curcas is much more important when increasing the dose of NPK or dung cache. These assumptions were confirmed by the work of Reinhardt [14] who performed the work under the present conditions of cultivation of J. curcas with the use of NPK 48-19-53. In the first year of cultivation of J. curcas seed yield is almost zero. Similar results were found by several authors where the yield of dry seeds to $5.8 \%$ moisture $\left(\mathrm{t} \mathrm{ha}^{-1}\right.$ year $^{-1}$ ) scenario reflecting the current crop of $J$. curcas and the scenario with the route optimization technique is $0 \mathrm{t} \mathrm{ha}^{-1}$ year $^{-1}$ of first grade. But when we improve the technical conditions and climate we can expect higher production yield of J. curcas. May be in the second year, we can expect a production of $J$. curcas. It was noted by several authors that the yield of $J$. curcas is more important from the second year. It note the work of Gokhale [15] who has done work for several years (1986-2003) in the region of Nashik in India (rainfall of $610 \mathrm{~mm}$ year $^{-1}$ ) over a total area of more than 8000 ha and has reported an average yield of less than $500 \mathrm{~kg}_{\text {acre }}{ }^{-1}$ (with varieties of different origins. not sharp) less than $1.250 \mathrm{~kg} \mathrm{ha}^{-1}$ of dry seeds trees in full production after 7 years of cultivation. The last observation made by Henning R. [16] in Cambodia reported on $2.8 \mathrm{~kg}$ of seeds per plant per harvest. This observation was made on a plantation of 10 ha in full aged 3 years. The annual returns and consequently to more than $5 \mathrm{t} \mathrm{ha}^{-1}$ of seeds with a density of 1.300 plants $\mathrm{ha}^{-1}$. At the conference of Wageningen [16] researchers working on J. curcas from around the world agreed on a scale of return of 3 to $5 \mathrm{tha}^{-1}$ year ${ }^{-1}$. It raises the question whether the marginal soils of the Sudano-Sahelian can have these returns because of the severe climate and poor soils. We believe that the plant irrigation during the dry period could improve the yield of $J$. curcas on degraded soils in North Cameroon.

4.4 Biomass, Sequestration of Carbon with Association of Culture of J. curcas and V. unguiculata in Marginal Soils in Garoua Region of Cameroun

The biomass production and yield in cultivated $J$. curcas spacing of $V$. unguiculata is low. In this study the effects of recovery is not felt on the seed yield of $V$. unguiculata. But in the second year we will expect a reduction in $V$. unguiculata production. 
Association of $J$. curcas and $V$. unguiculata is important because the yield of this association is highly.

\subsection{Problems of Plant Mortality of J. curcas in} Marginal Soils

The infection period of $J$. curcas is drastic in the marginal soils of Garoua Region. The period of maximum parasite attack seedlings of $J$. curcas is between September and October. The plants associated with $V$. unguiculatas are much more vulnerable to attacks. The erratic rainfall has the second cause of mortality rate of seedlings of $J$. curcas in the field at Sanguéré-Paul. The solution we advocate is to water the plants during the first two months of planting and sowing until the onset of the rains in August this year.

The third problem of mortality of J. curcas is the quality of soil of Sanguéré. It has a negative influence on growth and development of J. curcas. If the soil is too degraded, the size, the diameter, the basal area, the ramifications, the number of leaves are less important especially when it came to control treatments without the use of chemical or organic fertilizers.

\section{Conclusions and Recommendations}

Germination rate of seeds of J. curcas on the boards increased to $95 \%$. The germination rate of seeds after direct seeding passed to $40 \%$. The survival rate of boards is $94.14 \%$ and that of direct seedling is $81.56 \%$. A low mortality of seedlings and direct seedling propagator are usually due to biotic such as insects. The doses of NPK $100 \mathrm{~g} /$ plant and cow dung $2 \mathrm{~kg}$ plant $^{-1}$ improve the number of branches of $J$. curcas. There is a positive correlation between branch number and yield of J. curcas. F4GeCn treatment has good biomass yield $\left(2.27 \pm 1.22 \mathrm{t} \mathrm{ha}^{-1}\right)$ and seeds $(1.60 \mathrm{t}$ $\mathrm{ha}^{-1}$ ) of $V$. unguiculata. This result shows that the dose of $2 \mathrm{~kg}$ of cow dung associated with the propagator technique improves the culture of J. curcas associated with $V$. unguiculata. The recovery plant of $J$. curcas is very important to the treatment $\mathrm{F} 2 \mathrm{GeCn}$. F0GeCn treatment has a significant biomass fresh $V$. unguiculata while for seed production is rather of F2SeCn treatment. The combination of $V$. unguiculata and $J$. curcas cultivation has a good performance. It produces pods very vigorous and very healthy seeds. However, J. curcas does not germinate easily on marginal soils with direct seeding. It is important to better advise the propagator to farmers because it is less frustrating and more controlled. For a good yield in $V$. unguiculata and J. curcas on degraded soils in the Sudano-Sahelian zone should be increased densities of $J$. curcas for different types of treatments and soil. It is important to increase different doses (2.5; 3 ; 3.5 and $4 \mathrm{~kg} \mathrm{plant}^{-1}$ ) of cow dung which seem to induce a positive and lasting performance of J. curcas.

\section{Acknowledgments}

Thanks a lot to IRAD and Sodecoton of Garoua for their collaboration and the financial support of this project.

\section{References}

[1] Tchobsala, A. A. J. M. J. 2008. Inventaire des variétés de $J$. curcas dans la zone cotonnière du Nord Cameroun. Rapport de la Mission du 13 au 26 mars 2008, 34, 2008.

[2] Tchobsala, J. P. L. J. W., Prudent, P., Mana, P., Meguéni, C., Djonbada, P., and Nenwola, K. B. 2009. Cultures de diversification dans la zone cotonnière du nord Cameroun; synthèse des résultats de la campagne expérimentale 2008/2009. 28 p.

[3] Afonso, J. 2007. Reporte final sobre los modulos de viveros y establecimiento de parcellas expérimentales de pinon higuerilla y girasol en el proyecto piloto de producion de biocombustibles gota verde. Por FHIA.

[4] Brown, S., Gillespie, A. J. R., and Lugo, A. E. 1989. "Biomass Estimation Methods for Tropical Forests with Applications to Forest Inventory Data." For. Sci. 35: 881-902.

[5] Henry, M., Picard, N., Trotta, C., Manlay, R. J., Valentini, R., Bernoux, M., and Saint-André, L. 2011. "Estimating Tree Biomass of Sub-Saharan African Forests: a Review of Available Allometric Equations." Silva Fennica 45 (3B): 477-569.

[6] Tchobsala, M. M., and Souaré, K. 2014. "Impact of Wood Logging on the Phytomass and Carbon 

Vigna unguiculata in Marginal Soil of Garoua Region, Cameroon

Sequestration in the Guinea Savanna of Ngaoundéré, Adamaoua Region of Cameroon." Global Adv. Res. Journ. Env. Sci. Toxic. 3 (3): 038-48.

[7] Saturnino, H. M. 2005. "Cultura do pinhao-manso (J. curcas L.)." Cultivation of J. curcas L. Informe Agropecuario 26 (229): 44-78.

[8] Aruna, R., Prakash, J. S. P., Jitendra, C., and Girish, B. N. 2007. "Floral Biology and Flower in Behaviour of $J$. curcas.” In: Expert Seminar on J. curcas L. Agronomy and genetic. Wageningen: Fact Fundation.

[9] Sharma, G. D., Gupta, S. N., and Khabiruddin, M. 1997. Cultivation of $J$. curcas as a Future Source of Hydrocarbon and Other Industrial Products. In Biofuels and Industrial Products from J. curcas. Gübitz, G. M., Mittelbach, M., Trabi, M. (eds), 19-21, DBV Graz.

[10] Heller, J. 1996. Physic nut. J. curcas L. Promoting the Conservation and Use of Underutilized and Neglected Crops. In Institute of Plant Genetic and Crop Plant Research. Gatersleben. Germany and International Plant Genetic Resource Institute, 88, Rome. Italy.

[11] Patolia, J., Arup, G., Jitendra, C., Chaudhary, D. R., Parmar, D. R., and Bhuva, H. M. 2007. Response of $J$. curcas Grown on Wasteland to $\mathrm{N}$ and P Fertilization. In Expert Seminar on J. curcas L. Agronomy and Genetics, 2007.
[12] Suhas, P., Wani, T., and Sa, T. 2006. Biodiesel-based Opportunities to Rehabilitate Degraded Lands and Income Generation. Presentation Biopower Wanietal Biodiesel. I. ICRISAT. Editor. Fact_Fondation. Jatropha Handbook First Draft, 45, 2006.

[13] Fact_Fondation. Jatropha Handbook First Draft, 45, 2006.

[14] Reinhardt, G. I., Becker, K. (University of Hohenheim), and Gosh, A. (CSMCRI). Basic Data for Jatropha Production and Use Updated Version. IFEU. Institute for Energy and Environmental Research Heidelberg gGmbh. CSMCRI Central Salt \& Marine Chemical Research Institut. Bhavnagar. University oh Hohenheim Institut of Animal Production in the Tropics and Subtropics. Saturnino, H. M., Cultura do pinhao-manso (J. curcas L.). Cultivation of J. curcas L. Informe Agropecuario 26 (229): 44-78.

[15] Gokhale, D. 2008. Jatropha: Experience of Agro-Forestry \& Wasteland Development Foundation. Nashik. India. In International Consultation on Pro-poor Jatropha. Development. Rome: Syngenta International.

[16] Henning, R. 2007. Identification, Selection and Multiplication of High Yielding Jatropha curcas L. Plants and Economic Key Points for Viable Jatropha Oil Production Costs, in Site www.jatropha.de, 2007. 